\title{
A new 100-m Digital Elevation Model of the Antarctic Peninsula derived from ASTER Global DEM: methods and accuracy assessment
}

\author{
A. J. Cook ${ }^{1}$, T. Murray ${ }^{1}$, A. Luckman ${ }^{1}$, D. G. Vaughan ${ }^{2}$, and N. E. Barrand ${ }^{2}$ \\ ${ }^{1}$ Department of Geography, Swansea University, Swansea, SA2 8PP, UK \\ ${ }^{2}$ British Antarctic Survey, High Cross, Madingley Road, Cambridge, CB3 OET, UK \\ Correspondence to: A. J. Cook (577453@swansea.ac.uk)
}

Received: 13 April 2012 - Published in Earth Syst. Sci. Data Discuss.: 15 May 2012

Revised: 3 September 2012 - Accepted: 21 September 2012 - Published: 18 October 2012

\begin{abstract}
A high resolution surface topography Digital Elevation Model (DEM) is required to underpin studies of the complex glacier system on the Antarctic Peninsula. A complete DEM with better than $200 \mathrm{~m}$ pixel size and high positional and vertical accuracy would enable mapping of all significant glacial basins and provide a dataset for glacier morphology analyses. No currently available DEM meets these specifications. We present a new 100-m DEM of the Antarctic Peninsula $\left(63-70^{\circ} \mathrm{S}\right)$, based on ASTER Global Digital Elevation Model (GDEM) data. The raw GDEM products are of high-quality on the rugged terrain and coastal-regions of the Antarctic Peninsula and have good geospatial accuracy, but they also contain large errors on ice-covered terrain and we seek to minimise these artefacts. Conventional data correction techniques do not work so we have developed a method that significantly improves the dataset, smoothing the erroneous regions and hence creating a DEM with a pixel size of $100 \mathrm{~m}$ that will be suitable for many glaciological applications. We evaluate the new DEM using ICESat-derived elevations, and perform horizontal and vertical accuracy assessments based on GPS positions, SPOT-5 DEMs and the Landsat Image Mosaic of Antarctica (LIMA) imagery. The new DEM has a mean elevation difference of $-4 \mathrm{~m}( \pm 25 \mathrm{~m}$ RMSE) from ICESat (compared to $-13 \mathrm{~m}$ mean and $\pm 97 \mathrm{~m}$ RMSE for the original ASTER GDEM), and a horizontal error of less than 2 pixels, although elevation accuracies are lower on mountain peaks and steep-sided slopes. The correction method significantly reduces errors on low relief slopes and therefore the DEM can be regarded as suitable for topographical studies such as measuring the geometry and ice flow properties of glaciers on the Antarctic Peninsula. The DEM is available for download from the NSIDC website: http://nsidc.org/data/nsidc-0516.html (doi:10.5060/D47P8W9D).
\end{abstract}

\section{Introduction}

The Antarctic Peninsula differs from the rest of the continent in that it is a complex mountainous glacier system: outlet valley glaciers flow from a high elevation plateau region, draining to the east and west of the peninsula, either flowing into ice shelves or terminating as grounded or floating marine glaciers. The Global Land Ice Measurements from Space (GLIMS) glacier inventory of the Antarctic Peninsula comprises over 1100 individual glacier systems, including isolated ice caps, mountain glaciers and ice piedmonts (Rau et al., 2006). The behaviour of neighbouring marine- terminating glaciers is complex, as mass balance changes are affected not only by climate and oceanographic forcings but also by subglacial and surrounding topography. The tidewater glaciers throughout the Antarctic Peninsula have recently shown changes in extent, velocity and thickness (e.g. Rignot et al., 2004; Cook et al., 2005; Pritchard and Vaughan, 2007; Pritchard et al., 2009; Rott et al., 2011; Shuman et al., 2011; Berthier et al., 2012) but the changes in the mass balance of all individual basins have not yet been quantified. The response of glaciers to warming air-temperatures and ocean circulation changes in this region is critical for understanding future mass-balance changes, but the scale and 
inaccessibility of the region has hindered analyses both of the glacier system as a whole and of individual glaciers.

Digital Elevation Models (DEMs) are increasingly being used by glaciologists to investigate glacial features in regions that are difficult to access, and are commonly used to analyse spatial and temporal changes in the ice surface topography (e.g. Pope et al., 2007; Toutin, 2008; Nuth and Kääb, 2011; Frey and Paul, 2012). A topographic model of the Antarctic Peninsula glacier system would enable measurements such as area (through automated basin delineations), hypsometry, slope, aspect and flow direction, all of which are important in understanding ice dynamics, not only of individual flow units but of the complete glacier system. In recent years, DEMs of Antarctica have been produced using a range of source data including radar missions, stereo satellite image processing techniques and laser altimetry, but many of these elevation models have a spatial resolution of $1 \mathrm{~km}$ or greater and are optimised for coverage of the main Antarctic continent. This resolution is insufficient, however, for the smaller glaciers and the steep-sided coastal regions of the Antarctic Peninsula. A DEM of $\sim 100 \mathrm{~m}$ cell size, similar to the $90-\mathrm{m}$ Shuttle Radar Topography Mission (SRTM) DEM available for areas elsewhere on Earth, would be more suitable for the varied terrain in this region.

The ASTER Global Digital Elevation Model (GDEM) is a recently released nearly global high-resolution DEM, composed of elevation data generated automatically using photogrammetric principles and source data from the Advanced Spaceborne Emission and Reflection Radiometer (ASTER) stereo scenes (ASTER GDEM Validation Team, 2009). It is generally not considered for use in Antarctica due to the wellacknowledged large anomalies in these regions, introduced as a direct result of high reflectance and lack of features on snow-covered plateaus. Although it is therefore unsuitable for much of the interior of Antarctica, the Antarctic Peninsula has significant areas of exposed rock, varying surface slope and texture that suggest it will be better suited to this region. ASTER GDEM has a cell size of 1-arc second (equating to $\sim 10 \mathrm{~m}$ east-west and $\sim 30 \mathrm{~m}$ north-south in the Antarctic Peninsula) and, if the errors on the plateau regions can be sufficiently reduced, it could be considered as a useful new dataset for glaciological applications. Figure $1 \mathrm{a}$ and $\mathrm{b}$ shows a sample region that illustrates the ASTER GDEM compared against a visible-band image, the Landsat Image Mosaic of Antarctica (LIMA). The smoother, low-relief slopes visible on LIMA contain large spikes/pits on GDEM, whereas the higher-relief and greater texture coastal regions closely match the features visible on LIMA.

In this paper we describe a method that we have used to improve the ASTER GDEM dataset in the Antarctic Peninsula, and an assessment of the accuracy of the new DEM produced by this method. We begin by comparing existing DEM datasets in the Antarctic Peninsula and assess the suitability of each for glacial topography studies. We discuss the problems and inherent errors of GDEM, and discuss the fea-
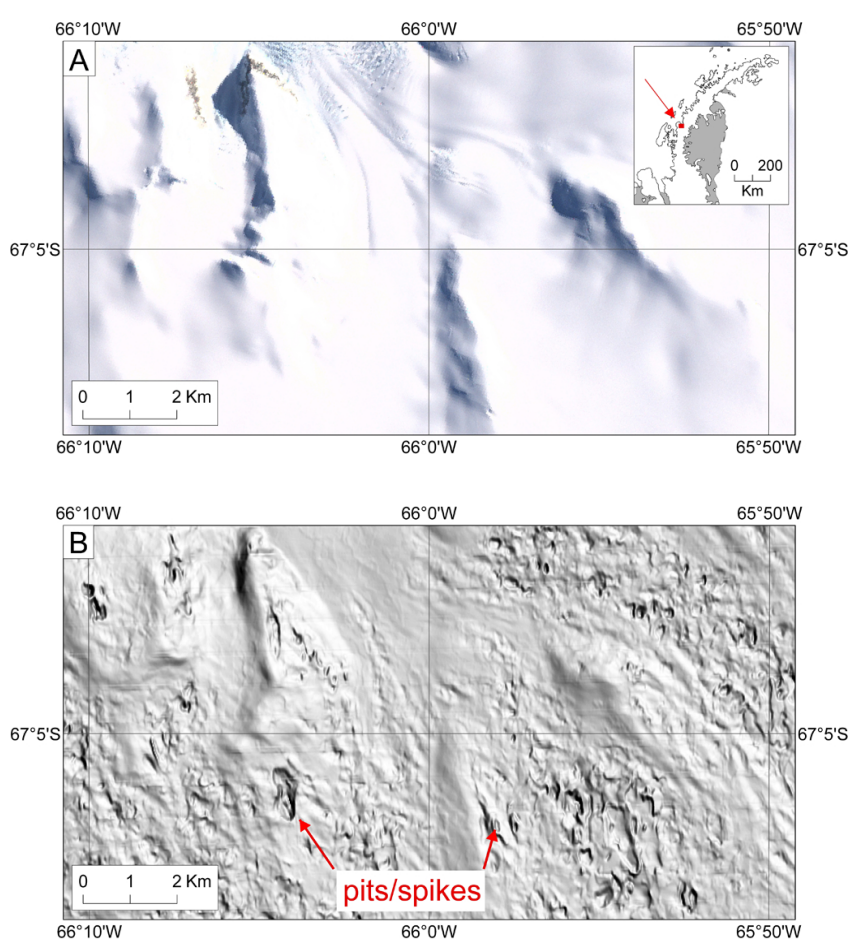

Figure 1. Sample area showing features visible on LIMA satellite image, displaying crevassed high-texture regions, rock outcrops and smooth surface low-relief slopes (A). The raw ASTER GDEM has been hillshaded to show the problems in the dataset such as pits/spikes, which primarily occur on the featureless surface slopes (B).

sibility of reducing these errors to produce a significantly improved DEM. The method that we have used to remove the artefacts in the data involves interpolating between contour data and combining these corrected regions with the higheraccuracy regions of GDEM. This unconventional technique is only used because standard filtering methods do not work in this region, and it is effective because GDEM outliers primarily occur on low surface slope regions, where the spikes and pits can be removed in order to smooth the surface. Accuracy tests reveal that the new DEM has errors that are significantly less than existing DEMs in the Antarctic Peninsula and it therefore has a broad applicability for glacier mapping and morphology studies. Indeed, the new DEM is already being widely used and included in Antarctic datasets, such as BEDMAP2.

\section{High resolution gridded elevation datasets for the Antarctic Peninsula}

In order to find a suitable DEM dataset for use in mass balance analyses in the Antarctic Peninsula, we considered those that are currently available to the international research community. Continent-wide DEMs that are widely used and provide reliable surface elevation data for much of 
Antarctica include the ICESat/GLAS $500 \mathrm{~m}$ DEM (DiMarzio et al., 2007) and the $1 \mathrm{~km}$ DEM from Combined ERS-1 Radar and ICESat Laser Satellite Altimetry (Bamber et al., 2009), but these are less reliable in the Antarctic Peninsula, with significant problems caused by the steeper topography and the coarser resolution. We chose to focus on DEMs with a better than $200 \mathrm{~m}$ grid-spacing for the level of detail required for the rugged terrain in this region. These include the Radarsat Antarctic Mapping Project (RAMP) v2 model (Liu et al., 2001) and the ASTER Global Digital Elevation Model (ASTER GDEM Validation Team, 2009). Regional DEMs are also available, including those produced from SPOT-5 High Resolution Sensor (HRS) stereoscopic data (Korona et al., 2009) and from elevation data collected as part of Operation IceBridge using the NASA/GSFC Land, Vegetation and Ice Sensor (LVIS) (http://lvis.gsfc.nasa.gov/index.html, 08/2012). High resolution Tandem-X Interferometric Synthetic Aperture Radar DEMs are currently being generated (Gantert et al., 2011) and Cryosat-2 Synthetic Aperture Interferometric Radar Altimeter (SIRAL) data (Cryosat: http: //www.esa.int/SPECIALS/Cryosat/, 08/2012) will be used for creating surface elevation grids, but at the time of writing these DEMs are not yet available for the Antarctic Peninsula. The Landsat Image Mosaic of Antarctica (LIMA), although not an elevation data source, has enabled identification of features at a spatial resolution of $15 \mathrm{~m}$ and it provides a base coastline from scenes that have a geospatial accuracy of $\pm 54 \mathrm{~m}$ RMSE (Bindschadler et al., 2008).

Of the regional DEMs, SPOT-5 stereoscopic survey of Polar Ice: Reference Images and Topographies (SPIRIT) is an International Polar Year (IPY) project in which a large archive of SPOT-5 HRS stereoscopic images and 40-m digital terrain models (DTMs) of Polar Regions were made available to the scientific community (Korona et al., 2009). Certain regions were chosen and prioritised before acquisition and the SPIRIT DTM products were generated automatically from the optical stereo-images through a matching algorithm. The DTMs were validated by comparison with ICESat elevation profiles, and for a highly-textured ablation region on the large outlet glacier in Greenland, Jakobshavn Isbrae, the SPIRIT DEM elevations (for non-interpolated pixels) were within $\pm 6 \mathrm{~m}$ of ICESat elevations, although the errors were greater on flat accumulation areas (Korona et al., 2009). The DTM products are at a high resolution and have a horizontal precision of $30 \mathrm{~m}$ RMS (Korona et al., 2009), but they only cover certain regions of the Antarctic Peninsula, primarily along the western coast and northern regions; therefore coverage is currently not sufficient to produce a DEM of the whole Antarctic Peninsula.

Of the two high-resolution products providing complete coverage, the Radarsat Antarctic Mapping Project (RAMP) v2 model (Liu et al., 2001), available from the NSIDC (http:// nsidc.org/data/nsidc-0082.html), is a DEM with widespread usage. It was originally created for use in processing images for the RAMP AMM-1 SAR Mosaic of Antarctica and since then has been widely used to map glaciological properties of the ice sheet (Jezek, 1999). The DEM accuracy varies according to the terrain and accuracy of the wide range of data sources, and uncertainties that are introduced through data integration. For the Antarctic Peninsula the geolocation accuracy is thought to be generally better than the horizontal resolution (200 $\mathrm{m}$ in this region), and the vertical accuracy lies between 100-130 m (Liu et al., 2001). Although RAMPv2 contains interpolated data, the source data in the Antarctic Peninsula is often of a sufficiently high resolution to make it a reliable surface topography dataset. The vertical accuracy required, however, for glacier drainage basin delineation for mass balance analyses on the Antarctic Peninsula must ideally be greater than those specified in the RAMPv2 documentation.

The ASTER Global Digital Elevation Model (GDEM) is the most recently released nearly global elevation dataset and is based upon a composition of automatically generated DEMs from ASTER stereo scenes acquired since 2000. It was produced by the Ministry of Economy, Trade and Industry (METI) of Japan and the United States National Aeronautics and Space Administration (NASA) and was first released to the public in June 2009 (ASTER GDEM Validation Team, 2009). ASTER consists of nadir and backward looking sensors, enabling a stereoscopic DEM to be generated based on photogrammetric principles. An automated approach was used to produce a stereo DEM between $83^{\circ} \mathrm{N}$ to $83^{\circ} \mathrm{S}$, in 1-degree tiles, with a pixel size of 1 -arc second. Validation tests were performed by both the US and Japanese partners by calculating statistical accuracies based on reference DEMs and Ground Control Points for sample regions around the globe. Conclusions in the validation summary report (ASTER GDEM Validation Team, 2009) are that the overall vertical accuracy of the ASTER GDEM1, on a global basis, is approximately $20 \mathrm{~m}$ at $95 \%$ confidence. With this pixel size and overall accuracy, GDEM could provide an attractive solution to finding a suitable DEM on the Antarctic Peninsula.

\section{ASTER GDEM: limitations and potential for use in the Antarctic Peninsula}

Although the majority of ASTER GDEM tiles have vertical accuracies within $20 \mathrm{~m}$, "ASTER GDEM does contain residual anomalies and artifacts that most certainly degrade its overall accuracy" (ASTER GDEM Validation Team, 2009). No formal GDEM validation has been performed over Antarctica, but it is evident that there are significant errors within the tiles throughout this region. This is to be expected, as the snow-covered landscape results in low contrast and sparse repeat coverage, both of which contravene the essential criteria for stereo-image processing. Prior glacier surface topography studies have encountered similar difficulties with photogrammetric methods in texture-less 


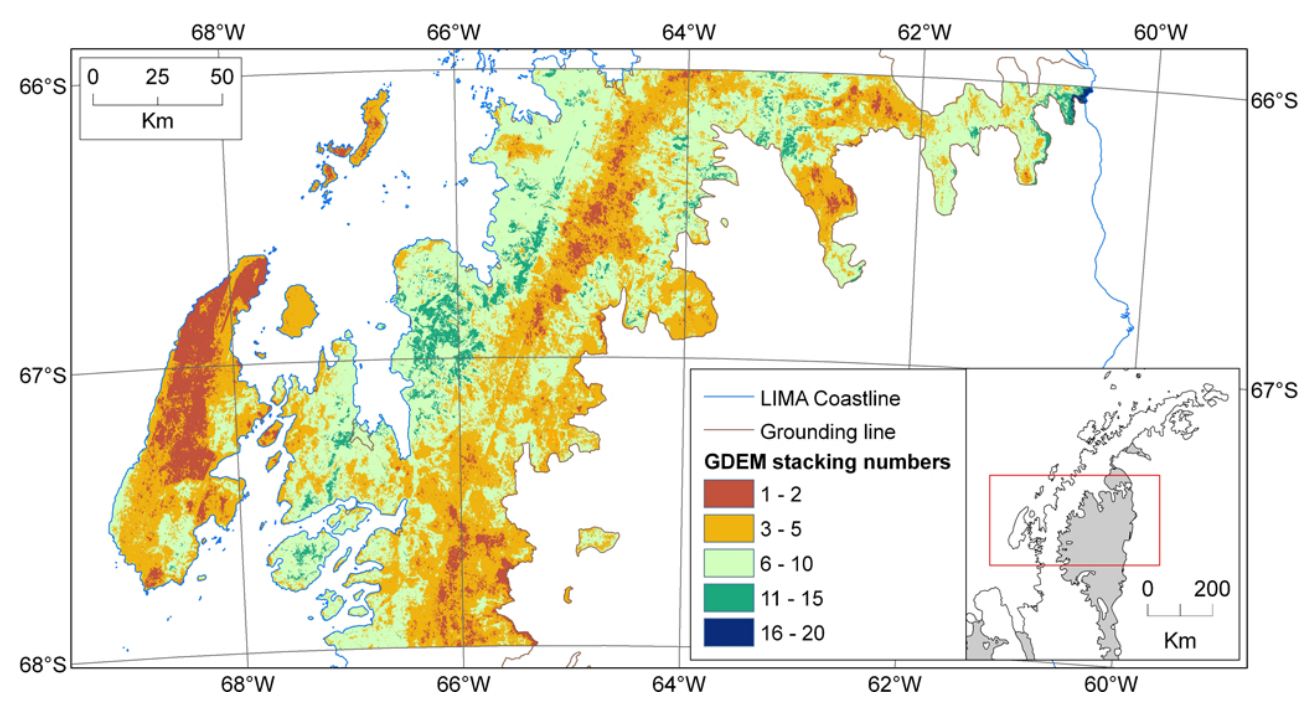

Figure 2. Number of stacked local DEMs (stacking number) used to calculate each GDEM elevation value for tiles between $66-68^{\circ} \mathrm{S}$. Stacking numbers of $\sim 6$ or higher are an indicator of higher DEM accuracy.

regions (e.g. Lodwick and Paine, 1985; Fox, 1995). Recent independent assessments of ASTER GDEM in Arctic regions (Hvidegaard et al., 2012; Rees, 2012; MacFerrin et al., 2012) have shown that the number of independent ASTER DEMs contributing to the final elevation value for any given pixel (known as the stacking number) is a good indicator of accuracy. In areas where this number is greater than $\sim 6$, the GDEM root-mean-square-error (RMSE) is typically 5$10 \mathrm{~m}$ (Rees, 2012). At high elevations on the Greenland Ice Sheet, however, where GDEM tiles are dominated by cloud and striping artefacts, the majority of points have low stacking numbers (Rees, 2012; MacFerrin et al., 2012). A study of GDEM accuracy in coastal regions of Greenland by Hvidegaard et al. (2012) showed that there was a bias of 10-20 m in the data and an RMSE elevation difference ranging from 15-65 m. Hvidegaard et al. (2012) attributed the large RMSE to low stacking numbers, reduced correlation between images due to snow cover, mis-registration between GDEM and the test dataset due to high sloping areas on the coast, and seasonal changes in the ice sheet. ASTER GDEM2 was released on 17 October 2011 and although it is a significantly improved version on a global scale (ASTER GDEM Validation Team, 2011), a comparison of GDEM1 and GDEM2 in Greenland concluded that there was insignificant difference in overall accuracy between the two versions in that region (MacFerrin et al., 2012).

Until now, GDEM has not been considered as a reference DEM for glaciological projects in Antarctica, although it has been used to derive elevations such as the ASAID grounding line (Bindschadler et al., 2011). As the potential for ASTER DEMs to be used for glacier-change studies in the Antarctic Peninsula is becoming more recognised (e.g. Cziferszky et al., 2010; Glasser et al., 2011; Shuman et al., 2011; Scambos et al., 2011), it is important to consider how the GDEM arte- facts can be reduced. For Greenland, recommendations for reducing errors include filtering regions where stacking numbers are low and cloud and striping artefacts are high, and either interpolating across remaining cells where the ice is relatively flat, or down sampling (MacFerrin et al., 2012). In some parts of the Antarctic Peninsula, however, if the "noise" was filtered there would be too few remaining postings for interpolation to be viable and valid elevations would be lost with down sampling. Figure 2 illustrates the stacking numbers of ASTER GDEM for a sample region of the Antarctic Peninsula between $66-68^{\circ} \mathrm{S}$, in which extensive regions with stacking numbers less than six can be observed.

The stacking number file that is provided with the elevation dataset also indicates regions that could be considered as high-quality and should be investigated further. When GDEM is contoured and placed over the LIMA, in some regions it fits closely to terrain features, particularly in coastal and feature-rich areas. Rock features, mountain slopes, crevasses and supraglacial water create texture for the image-matching algorithms, thereby increasing the stacking numbers of valid ASTER scenes per pixel. In other areas, often where the stacking numbers are low, the contours clearly do not fit terrain features and large pits and spikes appear. The contours are a way of visualising where the GDEM changes, often sharply, from good quality to poor. If the data are so noisy that they cannot be filtered or smoothed using recognised techniques such as a median filter method (as data quality is so variable across the modelled area) or methods described above, an alternative approach must be considered. 


\section{Methods}

\subsection{An alternative approach to ASTER GDEM correction}

A DEM generation approach already implemented in Antarctica used spatial interpolation algorithms within a Geographic Information System (GIS) environment to interpolate a surface between different vector data sources. The Radarsat Antarctic Mapping Project (RAMP) used a comprehensive collection of digital topographic source data - including cartographic data, remotely sensed data and survey data - which were then integrated and merged to produce the RAMP DEM (Liu et al., 1999). One data type that was used was contours digitised from paper topographic map sheets, included in the Antarctic Digital Database (ADD) (BAS et al., 1993). Contour-specific interpolation algorithms were tested by Liu et al. (1999), who found that the TOPOGRIDbased method (Hutchinson, 1989; ESRI, 1991) was the most effective technique in terms of consistency with the source contour data and preservation of fine surface structures. With this method, linear interpolation is enforced along ridge and stream lines, which are automatically derived from points of maximum curvature on contour lines (Liu et al., 1999). Although originally developed for use in ArcInfo, similar algorithms are now available in many GIS software packages.

The principle of the method we present in this paper is that when GDEM is converted into contours and the erroneous contours are removed, a smooth and realistic new DEM can be produced from the remaining contours. If this is applied only to regions with spurious contours, the resulting DEMs can be merged with the unaltered high-quality GDEM regions. The method is made possible by the fact that the high-artefact regions are those where the real surface slope is significantly less than $\sim 20^{\circ}$ (and therefore fewer contours are required to derive the new surface topography) and contours that are short in length can be removed from these regions since these represent spurious spikes and pits where the real-surface (as observed on LIMA) is smooth. Once the anomalous contours have been removed, those that remain can be used to reconstruct the surface topography by interpolation. This method was successfully applied in producing topographic maps of two regions of the Antarctic Peninsula (BAS, 2010a, b), but the method has not been previously published.

\subsection{ASTER GDEM correction procedure}

ASTER GDEM tiles were downloaded from http://gdem. ersdac.jspacesystems.or.jp/ and mosaicked according to each latitudinal degree across the Antarctic Peninsula. Each mosaic was projected onto a reference system suitable for minimising distortions in scale and for preserving angles locally. In this case, Lambert Conformal Conic (LCC) projection was used with standard parallels and other parameters according to latitude. The raw integer mosaic was converted to a 32-bit
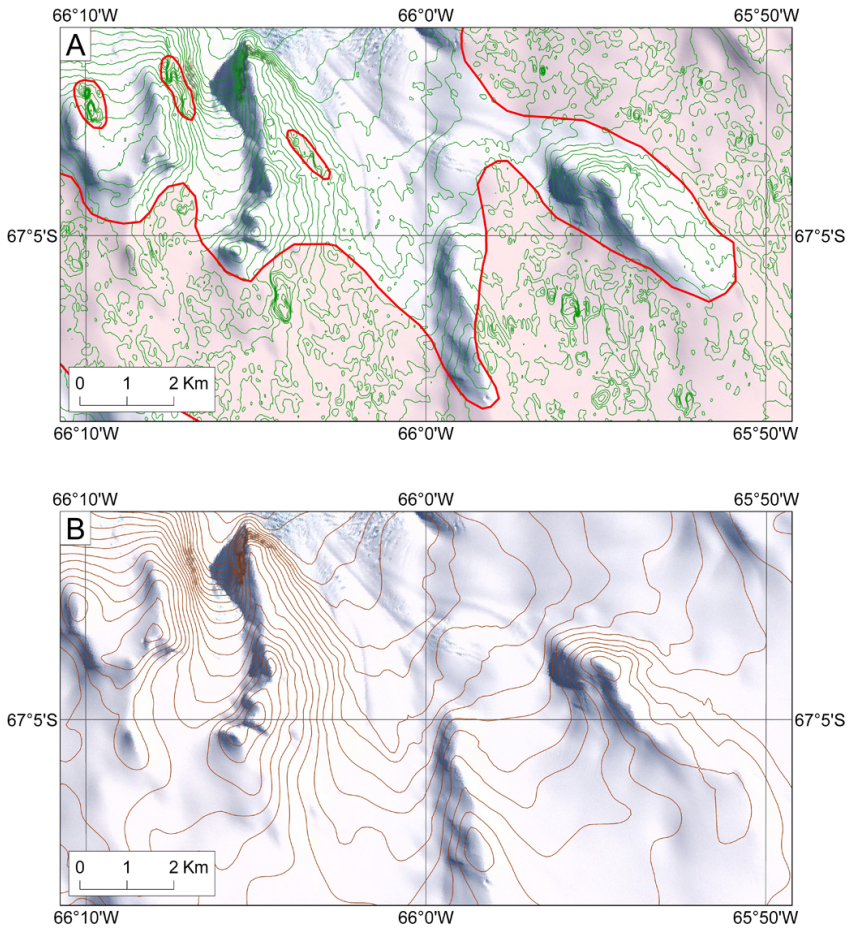

Figure 3. Sample area displaying $50 \mathrm{~m}$ contours generated from raw ASTER GDEM and error-region polygons (in pink) (A). This illustrates the first stage of the methodology: delineation of erroneous regions using contours draped over LIMA as a guide. The end-product has been contoured to illustrate the improvement in the DEM from the original and also the consistency of the topography at error region boundaries (B).

continuous floating point raster to minimise elevation errors introduced by rounding of values at each stage of data processing. The subsequent methodology was then applied separately to each latitudinal degree raster between $63-70^{\circ} \mathrm{S}$.

Using ArcGIS, contours were generated automatically from the GDEM at $20 \mathrm{~m}$ intervals. A new file was then created by digitising around regions of erroneous contours. The stacking number file was used to generate the initial outline of poor quality regions (where the stacking number is less than 6), but manual corrections were necessary using visible band imagery (in this case, LIMA) to visually assess how well the contours match the terrain (Fig. 3a). These "noisy" regions of the DEM were then extracted and down sampled to $200 \mathrm{~m}$ to simplify and, by using the ArcGIS "fill" and "lowpass filter" tools, sinks in the DEM were filled and gross errors removed. Contours at $20 \mathrm{~m}$ intervals were then created for this filtered DEM. In order to correct these contours two methods were applied. The first involved creating a slope model and removing contours that fell within a slope angle of greater than $20^{\circ}$ (this angle was chosen after testing various slope values). The second step involved deleting contours less than $1 \mathrm{~km}$ in length (chosen as the best indication of a spurious contour at this DEM cell size, after testing a range 
of values). In order to minimise discontinuity between the corrected regions and the high-quality regions, we created a $200 \mathrm{~m}$ overlap or "buffer" zone for all error-regions. The contours could then be manually checked and any remaining spurious contours deleted or improved based on the terrain visible in the LIMA image. It was then possible to generate a new DEM for the error-regions using the edited contour file. We did this using the Topo to Raster interpolation tool in ArcGIS, with a $100 \mathrm{~m}$ output cell size. In total, the edited region makes up $39 \%$ of the complete DEM coverage.

The outer limit we chose for the new DEM is the coastline that is visible on LIMA, plus a buffer of $500 \mathrm{~m}$ offshore. This means that all of GDEM is included, even where the horizontal positioning does not directly match LIMA. When GDEMv1 was produced a mask was applied, resulting in some coastal regions and almost all of the ice shelves being omitted from the finished product. The new DEM uses the Antarctic Surface Accumulation and Ice Discharge (ASAID) grounding line (Bindschadler et al., 2011) with a buffer of $500 \mathrm{~m}$ as a boundary where there is ice shelf. The highquality GDEM (i.e. the original GDEM with the erroneous regions removed) was resampled to $100 \mathrm{~m}$, and "filled" to remove minor pits. A cell size of $100 \mathrm{~m}$ was determined to be optimal: if the grid size is smaller, artefacts remain on the high-quality regions, whereas sufficient topographic detail can be obtained at this spacing for the complexity of terrain in the Antarctic Peninsula.

Finally, the corrected error-region DEM was mosaicked with the high-quality GDEM, using a weight-based blend to ensure a topographically consistent DEM across the buffer zones (Fig. 3b). Once these steps were completed for each individual latitudinal degree tile, a common reference system was selected before the tiles were integrated. For the Antarctic Peninsula, Polar Stereographic projection with a standard latitude of $71^{\circ} \mathrm{S}$ and a central meridian of $0^{\circ}$ was chosen. As the ASTER GDEM is referenced to the WGS84 ellipsoid and adjusted to the EGM96 geoid model, the new DEM is also on this reference system and therefore gives height with respect to the geoid. The final step of the process involved mosaicking all tiles by blending, and a low-pass filter was applied to smooth the entire raster and reduce the significance of anomalous cells. Finally, any remaining artefacts along the coast were removed (i.e. assigned as "null" values), resulting in the finished DEM (Fig. 4).

\section{Error analysis}

In order to validate the new DEM, we carried out tests to assess vertical and horizontal positional accuracy. In Antarctica, assessing the quality of the derived surface can be problematic, as high-accuracy ground-control points are limited and poorly distributed throughout the modelled area. A first assessment of ASTER GDEM tiles was undertaken by Reuter et al. (2009), in which ICESat elevations were used

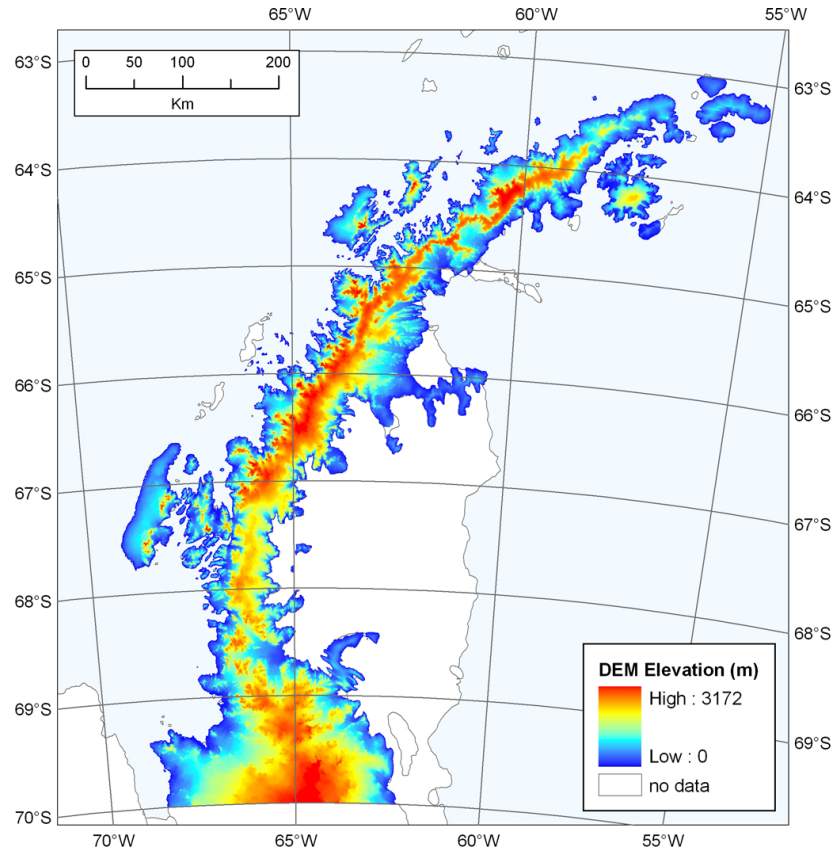

Figure 4. The new 100-m DEM of the Antarctic Peninsula.

for absolute accuracy tests and SRTM was used for relative accuracy for 5 GDEM tiles from around the globe. We applied a similar methodology here. We first addressed vertical accuracy, where we used ICESat as an absolute reference and compared elevations of existing DEMs across the spatial extent of the new DEM. Vertical accuracy according to slope was also assessed to detect any slope-dependent bias, and accuracies of both edited and unaltered regions were calculated to determine any significant differences from the mean errors. Horizontal accuracy tests included calculating absolute geospatial accuracy using 10 peaks in one small sample region based on GPS points and a photogrammetric DEM. Peaks obtained from SPIRIT DEMs gave relative accuracies across a wider region to test for consistency across the model. Finally, horizontal differences from LIMA were calculated for when the DEM is used alongside LIMA. See Table 1 as a reference for dataset acronyms.

\subsection{Absolute Vertical Accuracy}

The NASA Ice, Cloud and land Elevation Satellite (ICESat) mission from 2003-2009 consists of semi-continuous profiles of elevation points acquired using the onboard Geoscience Laser Altimeter System (GLAS) and provides consistent, near-repeat surface elevations (Zwally et al., 2002; Shuman et al., 2006). ICESat has a footprint of $\sim 70 \mathrm{~m}$ with an along-track spacing of $170 \mathrm{~m}$ and an across-track spacing of about $20 \mathrm{~km}$ at $70^{\circ} \mathrm{S}$. The high precision and sub-decimetre accuracies of the along-track elevation values on low-slopes (Shuman et al., 2006) are ideal for measuring absolute-errors and determining the accuracy of other 
Table 1. Summary of dataset acronyms.

\begin{tabular}{llr}
\hline Acronym & Definition & Pixel size \\
\hline ASTER GDEM & ASTER Global Digital Elevation Model & $\sim 20 \mathrm{~m}$ \\
New DEM & The new DEM of the Antarctic Peninsula derived from ASTER GDEM & $100 \mathrm{~m}$ \\
RAMPv2 & Radarsat Antarctic Mapping Project version 2 & $200 \mathrm{~m}$ \\
SPIRIT & SPOT-5 stereoscopic survey of Polar Ice: Reference Images and Topographies & $40 \mathrm{~m}$ \\
SPIRITv1 & SPIRIT DTM produced using parameters adapted for gentle topography & $40 \mathrm{~m}$ \\
SPIRITv2 & SPIRIT DTM produced using parameters adapted for rugged topography & $40 \mathrm{~m}$ \\
SPIRITv1 masked & SPIRITv1 with interpolated pixels removed. Masked version =83\% of SPIRITv1 & $40 \mathrm{~m}$ \\
SPIRITv2 masked & SPIRITv2 with interpolated pixels removed. Masked version =70\% of SPIRITv2 & $40 \mathrm{~m}$ \\
ICESat/GLAS & NASA Ice, Cloud and land Elevation Satellite/Geoscience Laser Altimetry System & $15 \mathrm{~m}$ \\
LIMA & Landsat Image Mosaic of Antarctica & \\
\hline
\end{tabular}

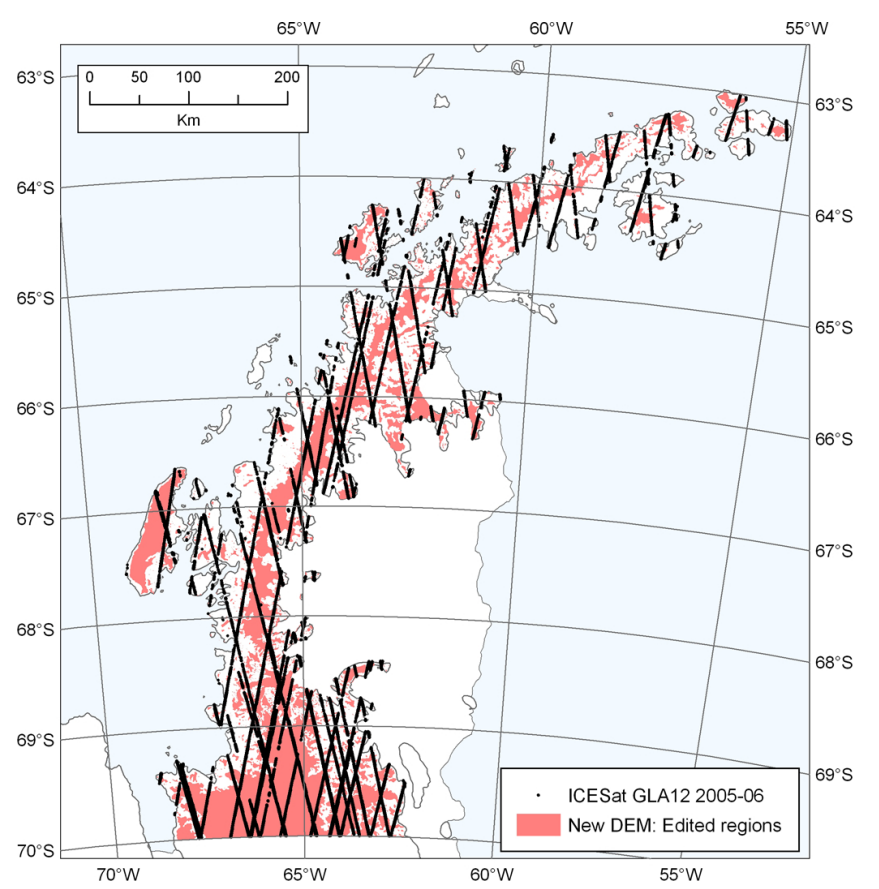

Figure 5. The edited regions are shown in pink, along with the ICESat tracks used for assessing the vertical accuracy of the new DEM.

elevation products (e.g. Korona et al., 2009; Nuth and Kääb, 2011).

We chose Release 28 GLAS/ICESat Global Elevation Data (GLA12), available from NSIDC (Zwally et al., 2003), for accurate surface ground-truth data across the range of terrain in the Antarctic Peninsula (Fig. 5). We used height measurements from laser periods 3A and 3B from 2005-2006, which had been corrected for pointing errors and saturation by Pritchard et al. (2009). Measurement precision over the ice sheets for uncorrected data has been found to vary with surface slope from 0.14 to $0.59 \mathrm{~m}$ (Brenner et al., 2007; Moholdt et al., 2010). After correction for errors, however, the residual uncertainty for the Release 28 data for the laser periods $3 \mathrm{~A}$ and $3 \mathrm{~B}$ in this region were reduced to $<0.1 \mathrm{~m}$ (Pritchard et al., 2009).

We chose ICESat elevations from 2005-2006 to correspond approximately with the years that SPIRIT scenes were acquired. GDEM, however, is compiled from ASTER scenes from a range of dates between 2000 and 2009 that are unspecified in the final product. Therefore, ice surface elevation change over time is a factor affecting relative elevation differences that must be recognised, even though it cannot be quantified. We calculated the surface elevation values of GDEM, the new DEM, SPIRIT DEMs (versions 1 and 2, both masked and unmasked) and the RAMPv2 DEM for each ICESat point. Each DEM is referenced to the WGS84 Ellipsoid and adjusted to the EGM96 Geoid. Although ICESat/GLAS uses a different ellipsoid (TOPEX/Poseidon), it results in elevation values only $70 \mathrm{~cm}$ higher than those obtained using the WGS84 Ellipsoid. The ICESat values have been corrected to the EGM96 Geoid.

All ICESat footprints that fall within the limit of the new DEM (Fig. 5) are used to compare elevations and residual uncertainties, as summarised in Table $2 \mathrm{a}$. The new DEM has a mean offset of $-4 \mathrm{~m}$, with an RMSE of $\pm 25 \mathrm{~m}$, which is a significant improvement to the original GDEM error values (mean $-13 \mathrm{~m}, \mathrm{RMSE} \pm 97 \mathrm{~m}$ ). RAMPv2 has significantly larger error values (mean of $-33 \mathrm{~m}$, RMSE of $\pm 201 \mathrm{~m}$ ). SPIRIT values are based on a mosaic of the SPIRIT tiles, where v1 is the version produced using parameters adapted for gentle topography, v2 for steeper topography and "masked" is where interpolated pixels have been masked-out (using reliability masks provided with the SPIRIT products) (Korona et al., 2009). It is important to calculate the accuracy of each SPIRIT product against ICESat before using them for further accuracy evaluations of the new DEM. Although the SPIRIT DEM mosaics have a relatively low mean offset from ICESat (ranging from 0 to $5 \mathrm{~m}$ ), they have a relatively high RMSE ( \pm 40 to $69 \mathrm{~m}$ ). This is greater than RMSE values reported in other evaluations of SPIRIT DEMs (e.g. Korona et al., 2009; Moholdt et al., 2010; Nuth and Kääb, 2011 and Shuman et al., 2011), but could be explained by the complex topography in this region 
Table 2a. Mean elevation differences from ICESat across the new DEM. $N$ is the number of ICESat points. The mean difference from each ICESat point is measured at height with respect to the EGM96 Geoid and the root mean square error (RMSE) is shown in metres.

\begin{tabular}{lccccccc}
\hline & New DEM & ASTER GDEM & RAMPv2 & SPIRITv1 & SPIRITv2 & SPIRITv1 masked & SPIRITv2 masked \\
\hline$N$ & 64593 & 64280 & 64747 & 16901 & 16915 & 13705 & 11127 \\
Mean & -4 & -13 & -33 & 4 & 0 & 5 & 4 \\
RMSE & \pm 25 & \pm 97 & \pm 201 & \pm 60 & \pm 69 & \pm 50 & \pm 40 \\
\hline
\end{tabular}

Table 2b. Comparisons between the new DEM and ASTER GDEM for both edited and non-edited regions (accuracies are relative to ICESat in metres). "Non-edited" signifies regions where the original GDEM is considered to be of high-quality. N.B. the new DEM was downsampled to $100 \mathrm{~m}$ and filtered in the "non-edited" regions, which explains the higher RMSE.

\begin{tabular}{lcccc}
\hline & \multicolumn{2}{c}{ Edited regions } & \multicolumn{2}{c}{ Non-edited regions } \\
\hline & New DEM & ASTER GDEM & New DEM & ASTER GDEM \\
\hline$N$ & 34858 & 34832 & 29735 & 29447 \\
Mean & -6 & -23 & -1 & -2 \\
RMSE & \pm 24 & \pm 129 & \pm 25 & \pm 19 \\
\hline
\end{tabular}

and changes in glacier surface heights between the dates of the data sources. Figure 6 shows comparison plots of the new DEM and GDEM against ICESat elevations. In addition, a sample along-track profile illustrates the differences between the DEMs and ICESat according to elevation, slope and terrain (Fig. 7) (further profiles can be seen in Supplement). The artefacts of the original GDEM are visible on the profile, particularly on the ice plateau regions, and it is clear that the new DEM closely matches the ICESat values in almost all sections of the profiles. From these absolute vertical error values we can conclude that the new DEM is a significant improvement over existing surface topography models of the Antarctic Peninsula.

\subsection{Vertical accuracy for corrected vs. uncorrected regions}

Figure 5 shows the delineations of edited regions across the DEM. Comparisons can be made between GDEM and the new DEM for pre- and post-editing, both inside and outside these regions (Table 2b). Error values for the new DEM within edited regions (mean $-6 \mathrm{~m}, \mathrm{RMSE} \pm 24 \mathrm{~m}$ ) are similar to the areas outside the edited-polygons (mean $-1 \mathrm{~m}, \mathrm{RMSE} \pm 25 \mathrm{~m}$ ). This is in sharp contrast to the raw GDEM which has much greater error values (mean $-23 \mathrm{~m}$, RMSE $\pm 129 \mathrm{~m}$ ) inside the erroneous regions before editing, illustrating the improvement by the removal of pits and spikes. We can deduce that there is no systematic bias introduced as a result of the correction process.

\subsection{Vertical accuracy according to slope}

Vertical differences are highly slope-dependent. For example, a small horizontal offset between ICESat and the DEM can have a large effect on the vertical difference (i.e. on steep slopes there is much greater elevation change per horizontal distance), which could be misinterpreted as vertical error. In low-slope regions this will have less of an effect and so we can have far greater confidence that the error values are correct. The vertical error assessment was re-run according to a range of slope categories (Fig. 8a and b). The mean differences from ICESat follow a similar trend for all DEMs: a smaller mean error at low-slope angles, increasing with steepness of slope. The same is true for RMSE values, but the main difference is that GDEM has a very high RMSE at low-slope angle, steadily decreasing until it increases again at slopes $>30^{\circ}$. RAMPv2 has considerably higher mean and RMSE values than all other DEMs, and it is the only DEM to have a mean positive offset increasing with slope. The other DEMs begin to show a negative offset increasing with slope at $>\sim 30^{\circ}$. If values at a slope angle $>30^{\circ}$ are omitted from error-calculations, we can obtain a more reliable measurement of vertical accuracy unaffected by slope-dependent bias (Table 2c). However, without horizontal co-registration of the DEMs we cannot be sure whether the greater vertical offset as surface slope increases is actually increasing data error or greater vertical differences caused by mis-alignment.

\subsection{Horizontal accuracy}

If the DEM was shifted, rotated or re-scaled horizontally to fit ground-truth elevation data, it might give different vertical accuracy results. The problem with rectifying the DEM is that considerable distortion would occur in regions lacking ground-truth data and between gaps in the data. It is not possible to make a shift without first determining the scale and direction of horizontal offset across the complete DEM. A method outlined in Nuth and Kääb (2011) for co-registering DEMs centres on the fact that there is a 
Table 2c. Mean elevation differences from ICESat in regions with real-surface slope $<30^{\circ} . N$ is the number of ICESat points. Mean and RMSE are in metres and all datasets are with respect to the EGM96 Geoid.

\begin{tabular}{lccccccc}
\hline & New DEM & ASTER GDEM & RAMPv2 & SPIRITv1 & SPIRITv2 & SPIRITv1 masked & SPIRITv2 masked \\
\hline$N$ & 63799 & 63486 & 63953 & 16561 & 16575 & 13392 & 10825 \\
Mean & -4 & -13 & -32 & 3 & -1 & 5 & 3 \\
RMSE & \pm 22 & \pm 97 & \pm 199 & \pm 57 & \pm 66 & \pm 47 & \pm 33 \\
\hline
\end{tabular}
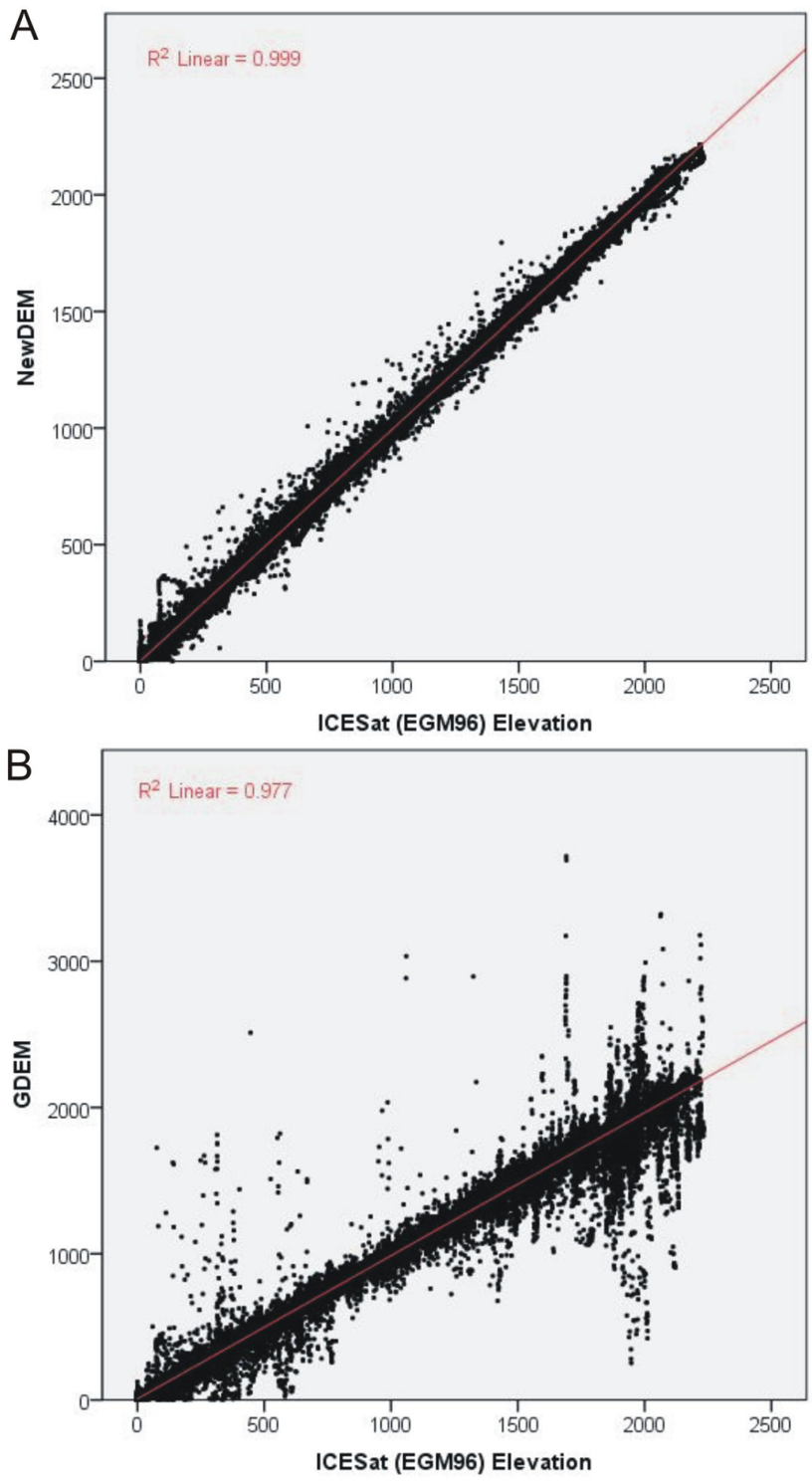

Figure 6. The relationship between ICESat footprint elevation values (in metres) and the new DEM (A) and the original ASTER GDEM before correction (B).

characteristic relationship between elevation differences and the direction of the terrain (aspect), which is related to the $\mathrm{x}-\mathrm{y}$-shift between the two DEMs. The co-registration process involves computing slope, aspect and vertical differ- ences and fitting a curve between two DEMs to allow a shift of one DEM to match the other (with further corrections for elevation-dependent bias and/or cross/along-track geometry as required). Non-stable terrain must be excluded from these calculations. Nuth and Kääb (2011) also suggest that this method can be applied using elevation data points, such as ICESat. Although this is a valuable way of co-registering datasets, there are two reasons that this cannot be applied to the new DEM:

1. The area of stable terrain across the Antarctic Peninsula DEM region is only $3.15 \%$ (as calculated using rock outcrop data available in the ADD).

2. The sample size will be reduced further by the scarcity of ICESat footprints that fall within these regions. The co-registration of the new DEM to these few points would not be valid.

If the new DEM cannot be co-registered to ground-truth elevation data, alternative tests must be carried out to assess horizontal accuracy. These tests can be based on the positions of mountain peaks since they are easily identifiable on each DEM. Although GPS points are limited, we can also use peaks detected on SPIRIT DEMs to obtain a sufficient coverage across the whole Antarctic Peninsula.

\subsubsection{Horizontal accuracy based on GPS points and a photogrammetric DEM}

Ryder Bay on Adelaide Island $\left(67.5^{\circ} \mathrm{S}, 68^{\circ} \mathrm{W}\right)$ (Fig. 9) was chosen as a sample region from which to ground truth geodetic height and horizontal positions, as it has been GPS surveyed and a DEM at $2.5 \mathrm{~m}$ resolution produced from aerial photographs. The GPS positions are better than $0.1 \mathrm{~m}$ in both horizontal and vertical accuracy and the photogrammetric DEM has a vertical accuracy of better than 0.5 m RMSE. The SPIRIT DEM does not cover this region, so only GDEM and the new DEM were compared to the Ryder Bay DEM. Although the sample region is small and only 10 peaks are used, the positions can give absolute-error values (Table 3). The horizontal mean difference from the pixel centres for the raw GDEM is $40 \mathrm{~m}$, and for the lower-resolution new DEM it is $64 \mathrm{~m}$ (i.e. below the $100 \mathrm{~m}$ pixel size). The mean vertical differences, however, are considerably greater than those calculated along the ICESat tracks. The mean peak difference for GDEM is $38 \mathrm{~m}$ lower, and for the new DEM is $77 \mathrm{~m}$ 

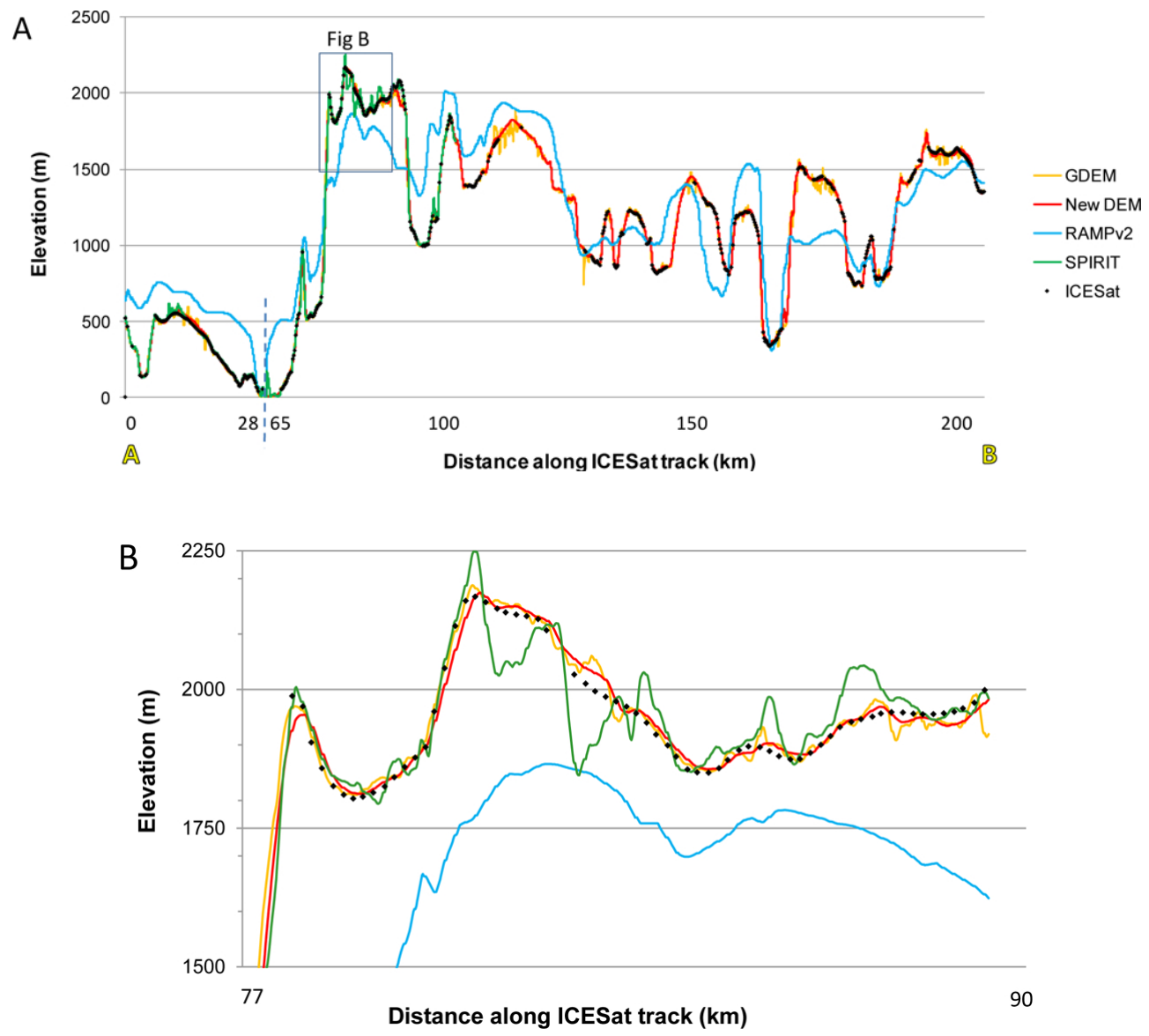

Figure 7. A profile along an ICESat track (GLA06_0144) crossing a range of topography on the Antarctic Peninsula illustrates relative differences between each DEM and ICESat elevations (A). Each DEM and the ICESat elevations are adjusted to the EGM96 Geoid. The SPIRIT DEM is based on version 2, unmasked. The inset (B) shows the differences in greater detail. The profiles for 4 other ICESat tracks and a map of the ICESat track locations can be found in Supplement. See Table 1 for acronyms.

Table 3. Absolute errors in the Ryder Bay region. The table shows the mean differences from the Ryder Bay DEM and GPS points for 10 peaks (metres).

\begin{tabular}{lrr}
\hline & GDEM & New DEM \\
\hline Horizontal & 40 & 64 \\
Vertical & -38 & -77 \\
\hline
\end{tabular}

lower than the absolute value. Previous studies have shown that ASTER DEM accuracy is highly correlated to the steepness of the terrain, where gross errors are likely to occur at steep slopes and high peaks (Kääb et al., 2002; Toutin, 2008; Cziferszky et al., 2010). Peak elevations on the new DEM have been further reduced during the resampling and filtering process.

\subsubsection{Relative accuracy and consistency tests using SPIRIT DEMs}

A wider assessment of geopositional accuracy can be carried out using SPIRIT DEMs, as they are well distributed across the new DEM. Although SPIRIT DEMs cannot be used for absolute error tests due to inaccuracies of their own (Korona et al., 2009), they can be used as a suitable reference dataset for relative accuracy and consistency tests across the new DEM. Section 2, Table 2 and Fig. 7 show the horizontal and vertical precision of SPIRIT DEMs. Based on the ICESat vertical accuracy test results, we chose to use SPIRITv2 (masked) as the most suitable DEM for the horizontal comparisons.

Figure 10 shows the location of SPIRIT tiles and the sample regions that we chose for relative error tests. Within each sample region, a number of peaks were identified on the SPIRIT DEMs, and the same peaks were then identified on the GDEM and the new DEM. The results are summarised in Table 4a and b. Firstly, using all 60 points from across the Antarctic Peninsula we show differences between GDEM 
A

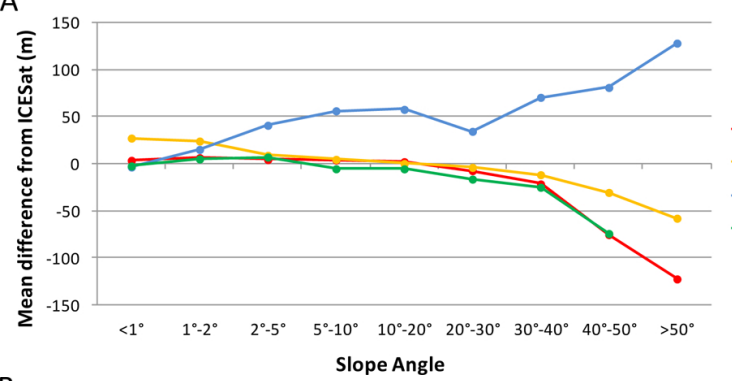

B

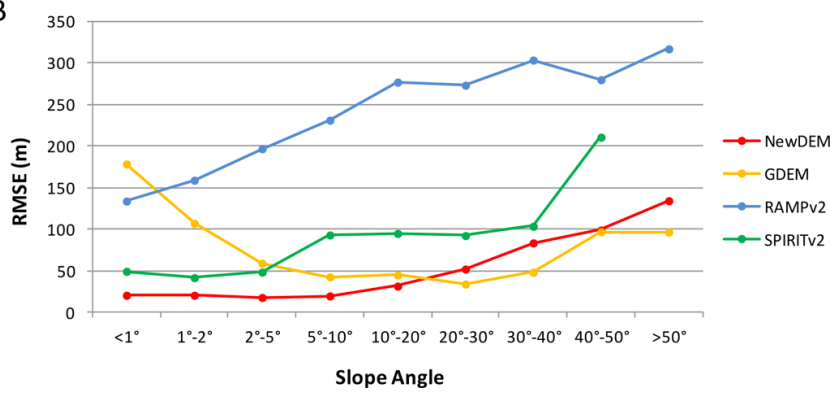

Figure 8. Mean difference of each DEM from ICESat categorized by slope (A); RMS errors categorized by slope (B).

and the new DEM relative to the SPIRIT DEMs. In each case the centre of the pixel is used as the geodetic position. The positions of the peaks on ASTER GDEM have a mean horizontal difference from their positions on the SPIRIT DEMs of $75 \mathrm{~m}(\mathrm{RMSE} \pm 48 \mathrm{~m})$ and the new DEM has a mean difference of $130 \mathrm{~m}$ (RMSE $\pm 59 \mathrm{~m})$. The peaks on ASTER GDEM have a mean vertical difference from the SPIRIT models of $-8 \mathrm{~m}(\mathrm{RMSE} \pm 24 \mathrm{~m})$ and those on the new DEM a difference of $-51 \mathrm{~m}(\mathrm{RMSE} \pm 25 \mathrm{~m})$. The reduction in height of peaks during the DEM editing process does not occur on lower relief slopes. The different resolution of the DEMs is one factor influencing the height differences (Kervyn et al., 2008). In order to assess the consistency throughout the new DEM, three regions can be compared (Table 4b). The mean horizontal difference is less than 2 pixels for each region (between $106-161 \mathrm{~m}$ ), and there is little variation in vertical errors, with mean heights ranging from 40 to $64 \mathrm{~m}$ below the SPIRIT DEM values.

\subsubsection{Horizontal differences from the Landsat Image Mosaic of Antarctica (LIMA)}

LIMA, at $15 \mathrm{~m}$ resolution, is often used as a base image for many glaciology studies so its geospatial accuracy relative to the DEMs must also be evaluated. The horizontal positions of the peaks on the SPIRIT DEMs were compared with their positions on LIMA. In addition to the Ryder Bay points, 25 positions along the coast of Ryder Bay were measured from LIMA and compared to the coast digitised from the photogrammetric DEM. The raw GDEM was used against which to compare LIMA as it has a higher resolution than the new

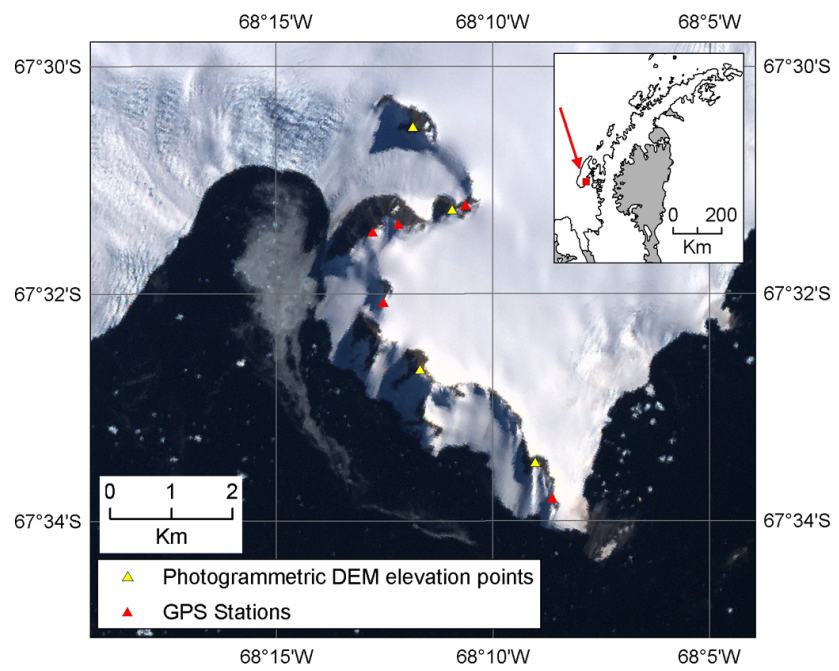

Figure 9. A map of the sample region Ryder Bay on Adelaide Island (location is shown on inset), displaying the location of GPS points and elevations derived from the high-accuracy photogrammetric DEM.

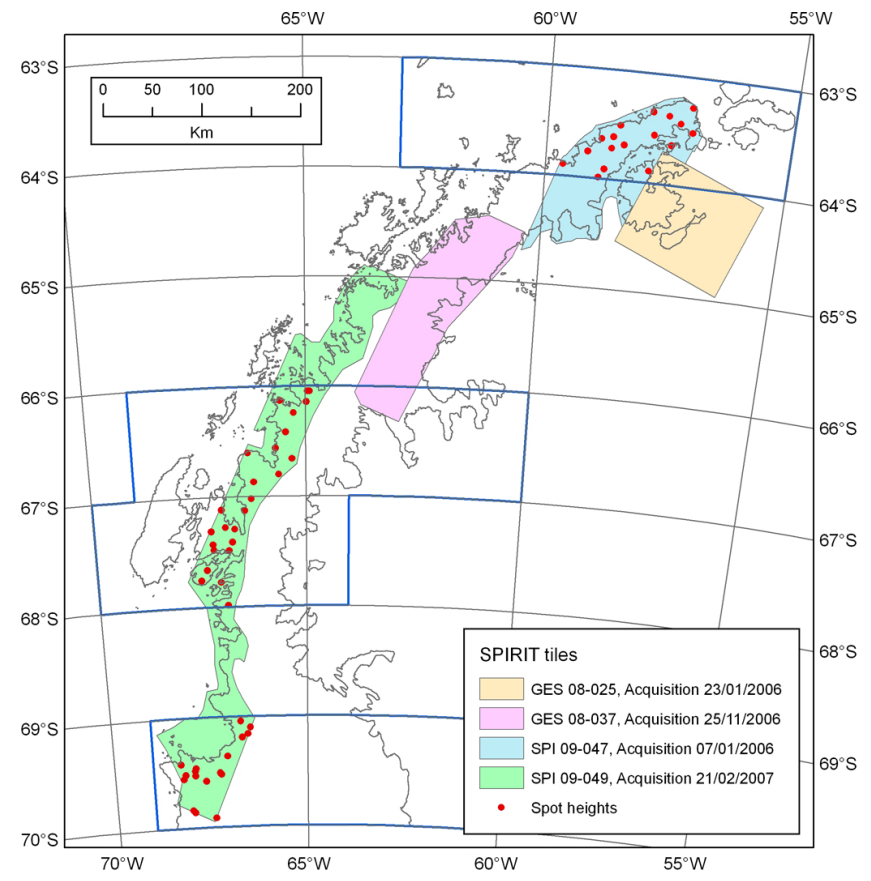

Figure 10. SPIRIT tile limits and their acquisition dates, plus the location of spot heights chosen for consistency and relative error tests.

DEM whilst sharing the same geolocation. LIMA has offset values from each dataset ranging from 81 to $110 \mathrm{~m}$, although it must be noted that the direction of offset is not consistent between datasets (Table 5). 
Table 4a. Relative errors. Values are a summary of the differences relative to SPIRIT DEMs for $\sim 60$ points distributed across the Antarctic Peninsula (in metres).

\begin{tabular}{llrr}
\hline & & GDEM & New DEM \\
\hline Horizontal & Mean & 75 & 130 \\
& RMSE & \pm 48 & \pm 59 \\
\hline \multirow{2}{*}{ Vertical } & Mean & -8 & -51 \\
& RMSE & \pm 24 & \pm 25 \\
\hline
\end{tabular}

\subsection{Methodology errors}

Some of the inaccuracies in the new DEM have been introduced through data processing methods. From the original GDEM tile, each process introduces the following horizontal differences:

- Reprojecting the original GDEM to LCC projection introduces a difference of $\sim 15 \mathrm{~m}$

- Resampling to $100 \mathrm{~m}$ reduces the horizontal precision by up to $\sim 50 \mathrm{~m}$

- Each tile was on an LCC projection with different parameters, so when re-projected onto Polar Stereographic before mosaicking, a further difference of up to $\sim 50 \mathrm{~m}$ was introduced

- The filter process caused "expansion" of up to $140 \mathrm{~m}$ at edges but did not change horizontal positioning within the DEM.

These processes can explain horizontal differences, but the principal vertical differences occur during the resampling and filtering processes. The average heights in regions of low-moderate relief were unaffected by smoothing, but the peaks and steep slopes were reduced in height. This can be explained by the relationship between elevation bias and maximum curvature of the slope: where slopes have low curvature values, the DEMs are equally represented at low- and high-resolution, whereas slopes with high curvature values are less well represented on coarser DEMs (Kervyn et al., 2008; Gardelle et al., 2012).

The new DEM is an improvement over existing surface topography models of the Antarctic Peninsula, but it comes with a few caveats. It has been corrected for the purpose of measuring glacier geometry, but it is not suitable for elevation change studies or accurate positional measurements of mountain peaks. This is largely because GDEM is from ASTER scenes spread between 2000-2009, meaning that seasonal and inter-annual differences in the ice surface are inherent in the data, and the RMSE value is too large to allow for precise surface measurements. Some anomalies along the coast have been removed, resulting in small gaps, and the DEM has a small number of remaining artefacts. It only cov-
Table 4b. Consistency tests, based on points obtained from SPIRIT DEMs in north, mid- and south Antarctic Peninsula regions (see Fig. 10). Values are mean differences in metres.

\begin{tabular}{lrr}
\hline & GDEM & New DEM \\
\hline $63-64^{\circ}$ S: 17 & points & \\
\hline Horizontal & 55 & 131 \\
Vertical & -6 & -44 \\
\hline $67-68^{\circ}$ S: 25 points & \\
\hline Horizontal & 67 & 106 \\
Vertical & -16 & -64 \\
\hline $69-70^{\circ}$ S: 17 points & \\
\hline Horizontal & 106 & 161 \\
Vertical & 4 & -40 \\
\hline
\end{tabular}

ers regions included in ASTER GDEM, in which there are inherent gaps and some missing islands.

\section{Conclusions}

We have presented a methodology in which anomalies inherent within ASTER GDEM have been significantly reduced to produce a new DEM for the Antarctic Peninsula between $63-70^{\circ} \mathrm{S}$. Although the technique is unconventional, it has enabled a new $100-\mathrm{m}$ DEM to be produced that is a demonstrable improvement over existing surface topography models of this region. This new representation of the surface could prove to be useful for many glaciological applications and is already being widely used and included in datasets. In this paper, we have validated the DEM by carrying out six accuracy tests, which highlight that whilst it has limitations, it is the first DEM with the spatial coverage, resolution and accuracy suitable for glacier morphology studies in the region. Absolute vertical accuracies taken from ICESat tracks from across the varied terrain on the Antarctic Peninsula show that the new DEM has a mean vertical error of $-4 \mathrm{~m}$, with an RMSE of $\pm 25 \mathrm{~m}$. Absolute accuracies within the edited regions are similar (mean $-6 \mathrm{~m}, \mathrm{RMSE} \pm 24 \mathrm{~m}$ ) so there is no apparent bias introduced through the editing process. Vertical values on peaks, however, were found to be significantly below real-values. This is as a result of the resampling and filtering processes, which are recognised to reduce elevation in regions with highcurvature of slope. Horizontal accuracies for the new DEM are below 2 pixels, as found in all error tests. The DEM is available for download from the NSIDC website: http: //nsidc.org/data/nsidc-0516.html (doi:10.5060/D47P8W9D) and a low resolution version of the new DEM is available from BEDMAP2: http://www.antarctica.ac.uk/bas_research/ our_research/az/bedmap2/index.php. 
Table 5. Horizontal differences (in metres) from the Landsat Image Mosaic of Antarctica (LIMA).

\begin{tabular}{lrrr|rrr|rrr}
\hline \multicolumn{2}{c}{ Ryder Bay (55 points) } & & \multicolumn{2}{c|}{ SPIRIT (60 peaks) } & \multicolumn{3}{c}{ GDEM (70 peaks) } \\
\hline & $x$ & $y$ & distance & $x$ & $y$ & distance & $x$ & $y$ & distance \\
\hline Mean & -81 & -69 & 110 & -25 & 4 & 94 & 18 & -10 & 81 \\
RMSE & \pm 39 & \pm 39 & \pm 41 & \pm 70 & \pm 84 & \pm 62 & \pm 59 & \pm 77 & \pm 56 \\
\hline
\end{tabular}

\section{Supplementary material related to this article is available online at: http://www.earth-syst-sci-data.net/4/ 129/2012/essd-4-129-2012-supplement.zip.}

Acknowledgements. This work was supported through an AXA Research Fund Fellowship. DGV and NB were supported by funding to the ice2sea programme from the European Union 7th Framework Programme, grant number 226375. Ice2sea contribution number 078. ASTER GDEM data are a product of METI and NASA and the GDEM tiles were acquired through the Earth Remote Sensing Data Analysis Center (ERSDAC). We are grateful to the LIMA Project for free download of LIMA tiles, to the National Snow and Ice Data Center (NSIDC) for access to ICESat/GLAS data and to Hamish Pritchard for kindly allowing us to use the ICESat/GLAS data he had processed. SPOT5 HRS data were provided by CNES/SpotImage France, through the SPIRIT International Polar Year project. We would like to thank the Mapping and Geographic Information Centre at the British Antarctic Survey, in particular Magda Biszczuk for initial ideas and discussions regarding the methodology, and Adrian Fox for his permission to use the GPS measurements for accuracy assessments. We are very grateful to the Antarctic Glaciological Data Center at NSIDC for their work on documenting and placing the DEM on their datasets website in an open access format. Finally, we would like to thank R. Drews and the anonymous referee who gave very thorough reviews and helpful suggestions to improve the quality of this paper.

Edited by: O. Eisen

\section{References}

ASTER GDEM Validation Team: METI/ERSDAC, NASA/LPDAAC, USGS/EROS, in cooperation with NGA and other collaborators, ASTER GDEM Validation Summary Report, available at: http://www.jspacesystems.or.jp/ersdac/GDEM/E/ image/ASTERGDEM_ValidationSummaryReport_Ver1.pdf, 2009.

ASTER GDEM Validation Team: ASTER Global Digital Elevation Model Version 2 - Summary of Validation Results, NASA Land Processes Distributed Active Archive Center and Joint Japan-US ASTER Science Team, available at: http://www.jspacesystems.or.jp/ersdac/GDEM/ver2Validation/ Summary_GDEM2_validation_report_final.pdf, 2011.

Bamber, J. L., Gomez-Dans, J. L. and Griggs, J. A.: Antarctic 1 km Digital Elevation Model (DEM) from Combined ERS-1 Radar and ICESat Laser Satellite Altimetry, Boulder, Colorado USA, National Snow and Ice Data Center, Digital media, 2009.
BAS, SPRI, and WCMC: Antarctic digital database user's guide and reference manual, Scientific Committee on Antarctic Research, Cambridge, 1993.

BAS: Adelaide Island and Arrowsmith Peninsula, 1:250 000 scale, BAS SR 19-20/14 (extended), British Antarctic Survey, 2010a.

BAS: Northern Antarctic Peninsula, 1:250000, BAS(UKAHT) Sheet 3A and 3B, 1 Edn., British Antarctic Survey, 2010b.

Berthier, E., Scambos, T. A., and Shuman, C. A.: Mass loss of Larsen B tributary glaciers (Antarctic Peninsula) unabated since 2002, Geophys. Res. Lett., 39, L13501, doi:10.1029/2012g1051755, 2012.

Bindschadler, R., Vornberger, P., Fleming, A., Fox, A., Mullins, J., Binnie, D., Paulsen, S. J., Granneman, B., and Gorodetzky, D.: The Landsat Image Mosaic of Antarctica, Remote Sens. Environ., 112, 4214-4226, doi:10.1016/j.rse.2008.07.006, 2008.

Bindschadler, R., Choi, H., Wichlacz, A., Bingham, R., Bohlander, J., Brunt, K., Corr, H., Drews, R., Fricker, H., Hall, M., Hindmarsh, R., Kohler, J., Padman, L., Rack, W., Rotschky, G., Urbini, S., Vornberger, P., and Young, N.: Getting around Antarctica: new high-resolution mappings of the grounded and freely-floating boundaries of the Antarctic ice sheet created for the International Polar Year, The Cryosphere, 5, 569-588, doi:10.5194/tc-5-569-2011, 2011.

Brenner, A. C., DiMarzio, J. R., and Zwally, H. J.: Precision and accuracy of satellite radar and laser altimeter data over the continental ice sheets, IEEE T. Geosci. Remote Sens., 45, 321-331, doi:10.1109/TGRS.2006.887172, 2007.

Cook, A. J., Fox, A. J., Vaughan, D. G., and Ferrigno, J. G.: Retreating glacier-fronts on the Antarctic Peninsula over the last 50 years, Science, 22, 541-544, 2005.

Cziferszky, A., Fleming, A., and Fox, A. J.: An assessment of ASTER elevation data over glaciated terrain on Pourquoi Pas Island, Antarctic Peninsula, in: Elevation Models for Geoscience, edited by: Gibbs, S., Geological Society Special Publications, 2010.

DiMarzio, J., Brenner, A., Schutz, R., Shuman, C. A., and Zwally, H. J.: GLAS/ICESat $500 \mathrm{~m}$ laser altimetry digital elevation model of Antarctica, Boulder, Colorado USA: National Snow and Ice Data Center, Digital media, 2007.

ESRI: Environmental Systems Research Institute, ARC/INFO User's Guide: Cell-based Modeling with GRID, Redlands, California, 1991.

Fox, A. J.: Using multiple data sources to enhance photogrammetry for mapping Antarctic terrain, Polar Res., 14, 317-327, 1995.

Frey, H. and Paul, F.: On the suitability of the SRTM DEM and ASTER GDEM for the compilation of topographic parameters in glacier inventories, Int. J. Appl. Earth Obs. Geoinf., 18, 480 490, doi:10.1016/j.jag.2011.09.020, 2012.

Gantert, S., Riegler, G., Teufel, F., Lang, O., Petrat, L., Koppe, W., and Herrmann, J.: TerraSAR-X, TanDEM-X, TerraSAR-X2 and 
their applications, Synthetic Aperture Radar (APSAR), 3rd International Asia-Pacific Conference, 1-4, 2011.

Gardelle, J., Berthier, E., and Arnaud, Y.: Impact of resolution and radar penetration on glacier elevation changes computed from DEM differencing, J. Glaciol., 58, 419-422, doi:10.3189/2012JoG11J175, 2012.

Glasser, N. F., Scambos, T. A., Bohlander, J., Truffer, M., Pettit, E., and Davies, B. J.: From ice-shelf tributary to tidewater glacier: continued rapid recession, acceleration and thinning of Rohss Glacier following the 1995 collapse of the Prince Gustav Ice Shelf, Antarctic Peninsula, J. Glaciol., 57, 397-406, 2011.

Hutchinson, M. F.: A new procedure for gridding elevation and stream line data with automatic removal of spurious pits, J. Hydrol., 106, 211-232, doi:10.1016/0022-1694(89)90073-5, 1989.

Hvidegaard, S. M., Sorensen, L. S., and Forsberg, R.: ASTER GDEM validation using LiDAR data over coastal regions of Greenland, Remote Sens. Lett., 3, 85-91, doi:10.1080/01431161.2010.527389, 2012.

Jezek, K. C.: Glaciological properties of the Antarctic ice sheet from RADARSAT-1 synthetic aperture radar imagery, Ann. Glaciol., 29, 286-290, 1999.

Kääb, A., Huggel, C., Paul, F., Wessels, R., Raup, B., Kieffer, H., and Kargel, J. S.: Glacier monitoring from ASTER imagery: accuracy and applications, EARSeL eProceedings No. 2, 43-53, 2002.

Kervyn, M., Ernst, G. G. J., Goossens, R., and Jacobs, P.: Mapping volcano topography with remote sensing: ASTER vs. SRTM, Int. J. Remote Sens., 29, 6515-6538, doi:10.1080/01431160802167949, 2008.

Korona, J., Berthier, E., Bernard, M., Remy, F., and Thouvenot, E.: SPIRIT. SPOT 5 stereoscopic survey of Polar Ice: Reference Images and Topographies during the fourth International Polar Year (2007-2009), ISPRS-J. Photogramm. Remote Sens., 64, 204212, doi:10.1016/j.isprsjprs.2008.10.005, 2009.

Liu, H., Jezek, K., Li, B., and Zhao, Z.: Radarsat Antarctic Mapping Project Digital Elevation Model version 2, National Snow and Ice Data Center, v2, 2001.

Liu, H. X., Jezek, K. C., and Li, B.: Development of Antarctic DEM by integrating cartographic and remotely sensed data: A GISbased approach, J. Geophys. Res., 104, 23199-23213, 1999.

Lodwick, G. D. and Paine, S. H.: A Digital Elevation Model of the Barnes Ice-Cap derived from Landsat MSS data, Photogramm. Eng. Remote Sens., 51, 1937-1944, 1985.

MacFerrin, M., Abdalati, W., and Scambos, T. A.: Summary of ASTER GDEM 1 and 2 errors on the Greenland Ice Sheet, with recommendations for scientific use, Remote Sens. Environ., in review, 2012.

Moholdt, G., Nuth, C., Hagen, J. O., and Kohler, J.: Recent elevation changes of Svalbard glaciers derived from ICESat laser altimetry, Remote Sens. Environ., 114, 2756-2767, doi:10.1016/j.rse.2010.06.008, 2010.

Nuth, C. and Kääb, A.: Co-registration and bias corrections of satellite elevation data sets for quantifying glacier thickness change, The Cryosphere, 5, 271-290, doi:10.5194/tc-5-271-2011, 2011.
Pope, A., Murray, T., and Luckman, A.: DEM quality assessment for quantification of glacier surface change, Ann. Glaciol., 46, 189-194, 2007.

Pritchard, H. and Vaughan, D. G.: Widespread acceleration of tidewater glaciers on the Antarctic Peninsula, J. Geophys. Res., 112, F03S29, doi:10.1029/2006JF000597, 2007.

Pritchard, H. D., Arthern, R. J., Vaughan, D. G., and Edwards, L. A.: Extensive dynamic thinning on the margins of the Greenland and Antarctic ice sheets, Nature, 461, 971-975, doi:10.1038/nature08471, 2009.

Rau, F., Kargel, J. S., and Raup, B.: The GLIMS Glacier Inventory of the Antarctic Peninsula, The Earth Observer, 18, 9-11, 2006.

Rees, W. G.: Assessment of ASTER global digital elevation model data for Arctic research, Polar Rec., 48, 31-39, doi:10.1017/s0032247411000325, 2012.

Reuter, H. I., Nelson, A., Strobl, P., Mehl, W., And Jarvis, A.: A first assessment of ASTER GDEM tiles for absolute accuracy, relative accuracy and terrain parameters, IEEE Int. Geosci. Remote Sensing Symposium, Cape Town, 12-17 July 2009, 1-5, 3665-3668, 2009.

Rignot, E., Casassa, G., Gogineni, P., Krabill, W., Rivera, A., and Thomas, R.: Accelerated ice discharge from the Antarctic Peninsula following the collapse of Larsen B ice shelf, Geophys. Res. Lett., 31, L18401, doi:10.1029/2004GL020679, 2004.

Rott, H., Müller, F., Nagler, T., and Floricioiu, D.: The imbalance of glaciers after disintegration of Larsen-B ice shelf, Antarctic Peninsula, The Cryosphere, 5, 125-134, doi:10.5194/tc-5-1252011, 2011.

Scambos, T. A., Berthier, E., and Shuman, C. A.: The triggering of subglacial lake drainage during rapid glacier drawdown: Crane Glacier, Antarctic Peninsula, Ann. Glaciol., 52, 74-82, 2011.

Shuman, C. A., Zwally, H. J., Schutz, B. E., Brenner, A. C., DiMarzio, J. P., Suchdeo, V. P., and Fricker, H. A.: ICESat Antarctic elevation data: Preliminary precision and accuracy assessment, Geophys. Res. Lett., 33, L07501, 10.1029/2005g1025227, 2006.

Shuman, C. A., Berthier, E., and Scambos, T. A.: 2001-2009 elevation and mass losses in the Larsen A and B embayments, Antarctic Peninsula, J. Glaciol., 57, 737-754, 2011.

Toutin, T.: ASTER DEMs for geomatic and geoscientific applications: a review, Int. J. Remote Sens., 29, 1855-1875, doi:10.1080/01431160701408477, 2008.

Zwally, H. J., Schutz, B., Abdalati, W., Abshire, J., Bentley, C., Brenner, A., Bufton, J., Dezio, J., Hancock, D., Harding, D., Herring, T., Minster, B., Quinn, K., Palm, S., Spinhirne, J., and Thomas, R.: ICESat's laser measurements of polar ice, atmosphere, ocean, and land, J. Geodyn., 34, 405-445, 2002.

Zwally, H. J., Schutz, R., Bentley, C., Bufton, J., Herring, T., Minster, J., Spinhirne, J., and Thomas, R.: GLAS/ICESat L2 Antarctic and Greenland Ice Sheet Altimetry Data, Digital Media, 2003. 